\title{
A study of the travel-activity behaviour of elders by activity-based approach
}

\author{
C.-W. Chu, H.-C. Hsia \& K.-Y. Yeh \\ Department of Urban Planning, \\ National Cheng Kung University, Taiwan
}

\begin{abstract}
Human life has been extended due to improvements in science and medical technology. It is recognized that most developed countries are facing the unique problems that come with an aging society. The problems associated with the medical treatment, care, and welfare of the elderly are steadily receiving more attention from the general public. However, little attention has been paid to the problems related to the living environments and transportation needs of the elderly. There is a lack of comprehensive research regarding the daily activity patterns of the elderly, though there is a good deal of research aimed at enhancing the mobility of the elderly. Therefore, this study recorded the daily life patterns of elderly individuals and the derived travel demands in those schedules by using an activity diary. This research used an activity-based approach as a framework. Stratified sampling method was used in the study area of Tainan City, Taiwan. Interview participants were chosen by purposive sampling method. The results show that: (1) Most of the elderly rely heavily on the private vehicle $(83.00 \%)$ which accounted for $51.57 \%$ of scooter, $34.21 \%$ of bicycle and $14.22 \%$ of car. Only a small percentage took public transportation (13.67\%). The participant's ability to drive a private vehicle appeared to have no influence on bus-taking behaviour, though a chi-square test showed some correlation with walking ability and gender. Those with good walking ability were more likely to take the bus. Furthermore, (2) the chi-square test revealed that walking ability and score on the IADL scale were significantly affected by age. (3) Nearly half of the time spent on leisure activities is passed by watching TV.

Keywords: activity-based approach, activity diary, the elderly.
\end{abstract}




\section{Introduction}

As science and medical technology have dramatically improved over the last century, the human life-span has been extended. According to the Population Projections, Taiwan is an "aging society." Over $7 \%$ of the population was elderly as of 1993 . That number is projected to be up to $14 \%$ by 2018 , and over $20 \%$ in 2025 [1]. A great deal of research has been done regarding the medical care and welfare of the elderly, but there is a need for more research regarding the transportation issues affecting the elderly.

Proper transportation and urban planning can provide a friendly traffic environment for the elderly, raising their mobility and access to essential services. Previous research indicates that transportation planning will play an important role in the ability of the elderly to engage in various out-of-home activities in the future $[2,3]$.

Analyzing activity demands and behaviours can allow for an investigation into the travel needs of the elderly. Using a behaviour theory methodology to understand traffic behaviour and traffic demands is necessary for further urban and transportation planning. Recent years have seen increased attention to traffic safety issues as they relate to the elderly $[4,5]$. Previous research reveals that the elderly have a very high accident rate. Burkhardt and McGavock [6] put forth a conservative estimate that the number of transportation-related fatalities will be 3-4 times greater in 2030 than it was in 1996.

Taiwan's traffic-related needs can be classified as follows: (1) To improve transportation information and design [7]. (2) To investigate user satisfaction with the transportation environment [8]. (3) To provide the elderly with suitable transportation services [9]. (4) To improve safety policies [5]. Though the cited studies have provided helpful information in regards to constructing a suitable transportation environment for the elderly, we still lack essential information about the individual daily transportation patterns of elderly people. According to Lin and Sie [10], there is a need to study the travel behaviours of the elderly in order to provide a suitable transport system for them. This research is an attempt to fill that gap through the framework of an activity-based approach.

The contents of this study include: (1) a description of the survey process, (2) analysis of the transportation behaviours, (3) activity time allocation of elderly people and (4) conclusion.

\section{Survey process}

Tainan City was the survey area for this research, and the participants were the elderly (aged 65 years or older). This study combined stratified sampling with purposive sampling methods to select participants.

\subsection{First stage of sampling: stratified sampling}

The first task for creating an appropriate sample was to define the proportion of the sample that should represent each district, and then using random sampling to 
demarcate the survey area for each village. What follows is a detailed description of this process: (1) Take the district as the stratified unit. (2) Decide the number of samples per district based on the proportion of elderly residents each district contains as it pertains the total elderly population. (3) The number of sample in each village is set up to 10 , and then confirm the how many village needed to investigate in each district. (4) Choose the representative village for each district by random sampling. The distribution of our survey area in Tainan City was as shown in Figure 1.

Moreover, we added 4 village units as spare one. So the total survey area is 36, shown as (5) in Table 1.

Table 1: $\quad$ Stratified random sampling process.

\begin{tabular}{|c|c|c|c|c|c|}
\hline & \multicolumn{4}{|c|}{ Pre-survey plans } & \multirow{2}{*}{$\begin{array}{c}\begin{array}{c}\text { Actual } \\
\text { circumstances }\end{array} \\
\text { 5 } \\
\text { Actual } \\
\text { number of } \\
\text { villages } \\
\text { surveyed }\end{array}$} \\
\hline & $\begin{array}{c}\text { (1) } \\
\text { Population } \\
\text { over } 65\end{array}$ & \begin{tabular}{|c|} 
(2) \\
Proportion of \\
total population
\end{tabular} & $\begin{array}{l}\text { (3) } \\
\text { Required number } \\
\text { of samples } \\
(=(2) \times \mathbf{3 0 0 *})\end{array}$ & $\begin{array}{c}\text { (4) } \\
\text { Number of random } \\
\text { villages to be } \\
\text { surveyed } \\
\text { (=3/10; rounded up) }\end{array}$ & \\
\hline East & 18,689 & $23.35 \%$ & 70 & 7 & 8 \\
\hline South & 15,304 & $19.12 \%$ & 57 & 6 & 6 \\
\hline North & 15,253 & $19.06 \%$ & 57 & 6 & 6 \\
\hline Annan & 14,405 & $18.00 \%$ & 54 & 6 & 8 \\
\hline Anping & 4,751 & $5.94 \%$ & 18 & 2 & 3 \\
\hline $\begin{array}{l}\text { West } \\
\text { Central }\end{array}$ & 11,644 & $14.55 \%$ & 44 & 5 & 5 \\
\hline Total & 80,046 & $100.00 \%$ & 300 & 32 & 36 \\
\hline
\end{tabular}

Data source: Websites for the household registration offices for the East District, South District, North District, Annan District, Anping District, and West District (July, 2013).

\subsection{Second stage of sampling: purposive sampling}

The first step confirmed specific survey areas. The second step of the sampling process focused on methods to find the elderly in the village. In order to enhance the efficiency of the investigation, our investigators first interviewed the village leader. After this interview, they asked for the following assistance: (1) Provide the contact details of the elderly in the village or the addresses of places of assembly. (2) Schedule interviews with the elderly residents. (3) Provide other information regarding volunteer clubs of the elderly.

If the village leader 'could not provide the above assistance, investigators proceeded as follows: (1) Discuss investigation with leaders of volunteer clubs. (2) Do a household survey. (3) Go to an open space, such as a park, and find the elderly.

Considering the enormous costs of household surveys, it's difficult to obtain the information for solitary elders using this method. We began surveying in November 2013 and finished in August 2014. Out of 462 questionnaires, 105 remained unanswered. This represented a $77.27 \%$ return rate. After deducting 27 invalid questionnaires, the total number of useable questionnaires was 330 . 


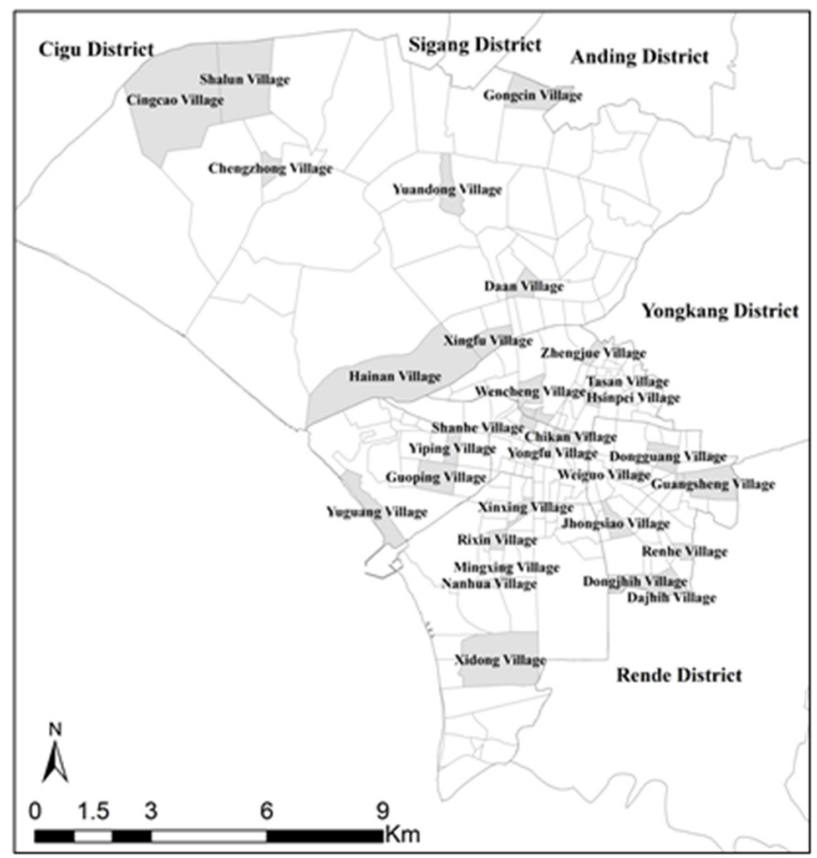

Figure 1: Locations of surveyed areas.

\section{Activity time allocation of elderly people}

\subsection{Basic data analysis}

Previous research indicates that elders travel outdoors less frequently than younger individuals do, mostly because of their age and increasing difficulty with walking [11-13]. Alsnih and Hensher [14] stated that the health of elders generally begins to deteriorate at the age of 75 . We therefore used this age to divide the participants into younger elders (65 to 75 years old) and older elders (over 75 years old) and conducted cross analysis and independence t tests on the walking abilities and IADLs of the two groups.

Walking ability was gauged by whether the respondent could walk for more than 30 minutes. An independence t test (details displayed in Table 2) was conducted on the results for the younger and older elders, which presented the two groups are correlated. As can be seen in Figure 2, approximately 32.84\% of the younger elders were able to walk for more than 30 minutes, whereas only $19.84 \%$ of the older elders were able to do so. Clearly, the walking ability of elders deteriorates with age.

To understand whether age affects the activities of elders, we used the IADL scale score to divide the participants into a severe disability group and a mild or no disability group. The former group displayed disability in more than half of the IADLs scale items ( $0-4$ points), whereas the latter showed disability in less 
than half of the items (5-8 points). We then tested the two groups (details in Table 3 ) and know the correlation exists between the two groups. Figure 3 shows that only $2.45 \%$ of the younger elders displayed severe disability, while $16.67 \%$ of the older elders presented severe disability. Clearly, the activities of elders are gradually affected by age.

Table 2: Cross-analysis of younger/older elders with walking ability.

\begin{tabular}{|l|c|c|c|}
\hline & $\begin{array}{c}\text { Can only walk for less than } \\
\mathbf{3 0} \text { min }\end{array}$ & $\begin{array}{c}\text { Can walk for more than } \\
\mathbf{3 0 ~} \text { min }\end{array}$ & Total \\
\hline Younger elders & $137(41.52 \%)$ & $67(20.30 \%)$ & $204(61.82 \%)$ \\
\hline Older elders & $101(30.61 \%)$ & $25(7.58 \%)$ & $126(38.18 \%)$ \\
\hline Total & $238(72.12 \%)$ & $92(27.88 \%)$ & $330(100.00 \%)$ \\
\hline
\end{tabular}

Note: $\chi^{2}(1)=6.549>\chi_{0.05}^{2}(1)=3.841$; thus, $H_{0}$ (the two groups are independent) is rejected.

Table 3: Cross-analysis of younger/older elders with extent of disability.

\begin{tabular}{|l|c|c|c|}
\hline & Severe disability & Mild or no disability group & Total \\
\hline Younger elders & $5(1.52 \%)$ & $199(60.30 \%)$ & $204(61.82 \%)$ \\
\hline Older elders & $21(6.36 \%)$ & $105(31.82 \%)$ & $126(38.18 \%)$ \\
\hline Total & $26(7.88 \%)$ & $304(92.12 \%)$ & $330(100.00 \%)$ \\
\hline
\end{tabular}

Note: $\chi^{2}(1)=21.687>\chi_{0.05}^{2}(1)=3.841$; thus, $H_{0}$ (the two groups are independent) is rejected.

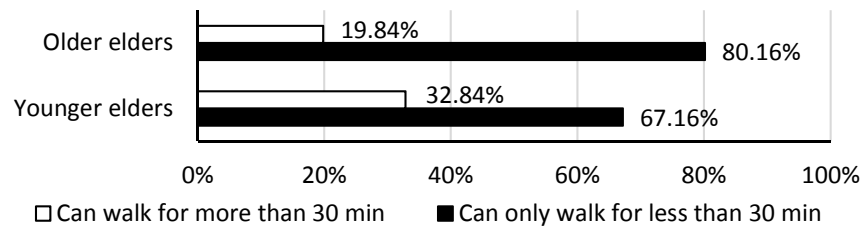

Figure 2: Walking abilities among younger/older elders.

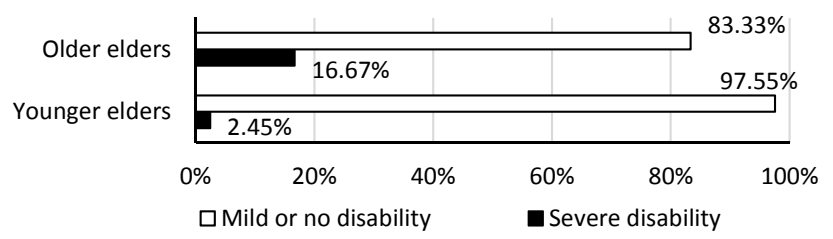

Figure 3: Extents of disability among younger/older elders.

We also performed an independent test on walking ability and IADLs (details in Table 4), which presented the correlation exists between the two groups. Approximately $29.93 \%$ of the members in the mild or no disability group could walk for more than 30 minutes, whereas only $3.85 \%$ of the members in the severe disability group could do so. Therefore, elders with more disabilities are less able to walk for more than 30 minutes (details in Figure 4).

The statistical analyses above allow us to establish connections among the age, walking ability, and IADLs among participants. Furthermore, comparisons of the various groups suggest that older elders have poorer activity and walking ability, which deteriorates with age. 
Table 4: $\quad$ Cross-analysis of walking ability with extent of disability.

\begin{tabular}{|l|c|c|c|}
\hline & $\begin{array}{c}\text { Can only walk for less } \\
\text { than 30 min }\end{array}$ & $\begin{array}{c}\text { Can walk for more } \\
\text { than 30 min }\end{array}$ & Total \\
\hline Severe disability & $25(7.58 \%)$ & $1(0.30 \%)$ & $26(7.88 \%)$ \\
\hline Mild or no disability & $213(64.55 \%)$ & $91(27.58 \%)$ & $304(92.12 \%)$ \\
\hline Total & $238(72.12 \%)$ & $92(27.88 \%)$ & $330(100.00 \%)$ \\
\hline
\end{tabular}

Note: $\chi^{2}(1)=8.107>\chi_{0.05}^{2}(1)=3.841$; thus, $H_{0}$ (the two groups are independent) is rejected.

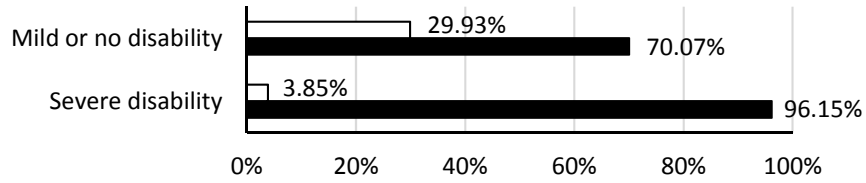

$\square$ Can walk for more than $30 \mathrm{~min} \quad$ Can only walk for less than $30 \mathrm{~min}$

Figure 4: Different levels of walking ability and different extents of disability.

\subsection{Analysis of transportation behaviour}

Studies conducted in developed countries indicate that the proportion of elders traveling by private modes of transportation is increasing, while the proportion traveling by public modes of transportation is decreasing [2, 15]. Although elders travel less frequently than younger people, they are extremely dependent on cars to do so $[11,16]$. Such results are common in research on the travel-activity behaviour of elders in other countries, and it is possible that elders in Taiwan would present the same results.

According to the report of Daily Use of Transport Survey in 2013 [17], point that elders in Taiwan are still relatively reliant on public transport when compared to individuals in other age groups (detail in Figure 5). Significant differences exist between the proportion of elders who use private vehicles and individuals between 30 and 60 years of age. Furthermore, roughly 4 out of 10 elders travel on foot. As can be seen, elders are still at a disadvantage when it comes to using different modes of transportation.

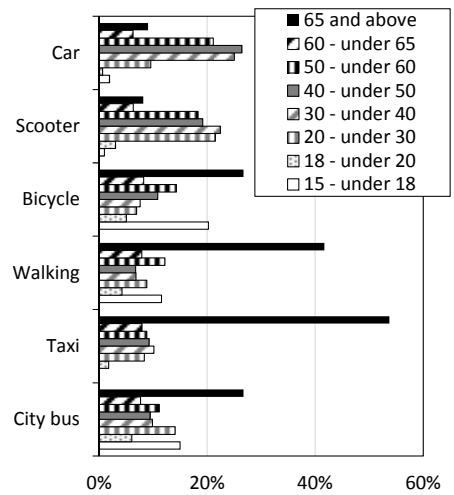

Different mode of transportation in elders

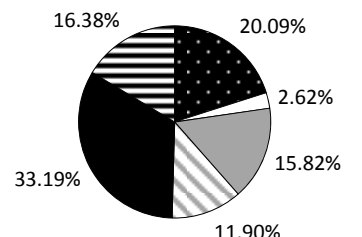

$11.90 \%$

- City bus $\square$ Taxi $\square$ Walking

Figure 5: Most commonly used mode of transportation. Data source: 2013 Daily Use of Transport Survey (reorganized). 
Examining the connections between the use of private vehicles and those of public transport or taxis can further understanding of the transportation behaviour of the elders within the study area. Below, we investigate (1) the use of private vehicles and (2) whether buses or taxis are taken.

\subsubsection{Use of private vehicles}

We divided the usage conditions into three types: can and do use, can but do not use, and cannot use. As shown in Table 5, the majority of the participants can and do use scooters $(64.85 \%)$, and a smaller proportion can and do use bicycles $(43.03 \%)$. In terms of private vehicles, $13.94 \%$ and $11.21 \%$ of the participants could but did not actually drive cars and ride bicycles, respectively. In contrast, a high $68.18 \%$ of the participants didn't know how to drive a car. Put simply, most of the elders did not have the ability to drive a car, which is a result that is inconsistent with those from foreign developed countries. Instead, scooters were the private vehicles most commonly used by elders.

Table 5: 'Use of private vehicles among elders.

\begin{tabular}{|l|c|c|c|}
\hline \multicolumn{1}{|c|}{ Vehicle type } & Bicycle (\%) & Scooter (\%) & Car (\%) \\
\hline Usage condition & $142(43.03 \%)$ & $214(64.85 \%)$ & $59(17.88 \%)$ \\
\hline Can and do use & $37(11.21 \%)$ & $21(6.36 \%)$ & $46(13.94 \%)$ \\
\hline Cannot do not use & $151(45.76 \%)$ & $95(28.79 \%)$ & $225(68.18 \%)$ \\
\hline Total & $330(100.00 \%)$ & $330(100.00 \%)$ & $330(100.00 \%)$ \\
\hline
\end{tabular}

\subsubsection{Use of buses and taxis}

In this analysis, we divided the participants into two groups based on whether they use private vehicles and then examined whether the two groups differ in how frequently they take the bus or taxis. The results show that 54 of the participants $(16.36 \%)$ do not use private vehicles, while 276 of the participants $(83.64 \%)$ do. Furthermore, the majority of the participants do not take buses $(86.19 \%)$ or taxis $(76.28 \%)$; only $12.91 \%$ and $22.82 \%$ take buses and taxis, respectively.

An independence $\mathrm{t}$ test on whether the participants use private vehicles or buses presented the correlation does not exist between the two groups (details in Table 6). An independence test on whether the participants use private vehicles or taxis presented the correlation does not exist between the two groups (details in Table 7). We can therefore conclude that whether a senior citizen uses private vehicles does not impact their use of buses or taxis.

It is possible that elders prefer scooters and bicycles due to the place where public transportation is inconvenient [18]. However, statistics indicate that

Table 6: Cross-analysis of whether private vehicles and buses are used.

\begin{tabular}{|l|c|c|c|}
\hline & Uses private vehicles & Does not use private vehicles & Total \\
\hline Takes the bus & $33(10.00 \%)$ & $10(3.03 \%)$ & $43(13.03 \%)$ \\
\hline Does not take the bus & $243(73.64 \%)$ & $44(13.33 \%)$ & $287(86.97 \%)$ \\
\hline Total & $276(83.64 \%)$ & $54(16.36 \%)$ & $330(100.00 \%)$ \\
\hline
\end{tabular}

Note: $\chi^{2}(1)=1.716<\chi_{0.05}^{2}(1)=3.841$; thus, $H_{0}$ (the two groups are independent) is not rejected. 
Table 7: Cross-analysis of whether private vehicles and taxis are used.

\begin{tabular}{|l|c|c|c|}
\hline & Uses private vehicles & Does not use private vehicles & Total \\
\hline Takes the taxis & $63(19.09 \%)$ & $13(3.94 \%)$ & $76(23.03 \%)$ \\
\hline Does not take the taxis & $213(64.55 \%)$ & $41(12.42 \%)$ & $254(76.97 \%)$ \\
\hline Total & $276(83.64 \%)$ & $54(16.36 \%)$ & $330(100.00 \%)$ \\
\hline
\end{tabular}

Note: $\chi^{2}(1)=0.400<\chi_{0.05}^{2}(1)=3.841$; thus, $H_{0}$ (the two groups are independent) is not rejected.

93\%of the people in Tainan City use private vehicles, so this may be a widespread phenomenon regardless of age.

We also conducted an independent test to determine whether the participant use of buses is associated with their walking ability. The results revealed that the correlation exists between the two groups (details in Table 8). As shown in Figure 6, elders that could not walk for 30 minutes occupied the greater majority of those that did not take the bus $(74.22 \%)$. This result shows that elders will likely forgo bus riding when they feel that their ability to walk is degrading.

Previous research also indicates that the travel-activity behaviour of most male elders comprises walking and scooter riding, whereas female elders mostly walk and take the bus due to their lack of ability to drive or ride $[17,18]$. We therefore performed an independence test on gender and whether a participant takes the bus (details in Table 9). Our results were consistent with those in previous research, showing that the majority of the elders that took the bus were female $(62.79 \%$, as shown in Figure 7$)$.

Table 8: Cross analysis of walking ability and whether buses are used.

\begin{tabular}{|l|c|c|c|}
\hline & $\begin{array}{c}\text { Can only walk for less } \\
\text { than 30 min }\end{array}$ & $\begin{array}{c}\text { Can walk for more than } \\
\mathbf{3 0} \text { min }\end{array}$ & Total \\
\hline Takes the bus & $25(7.58 \%)$ & $18(5.45 \%)$ & $43(13.03 \%)$ \\
\hline Does not take the bus & $213(64.55 \%)$ & $74(22.42 \%)$ & $287(86.97 \%)$ \\
\hline Total & $238(72.12 \%)$ & $92(27.88 \%)$ & $330(100.00 \%)$ \\
\hline
\end{tabular}

Note: $\chi^{2}(1)=4.807>\chi_{0.05}^{2}(1)=3.841$; thus, $H_{0}$ (the two groups are independent) is rejected.

Table 9: $\quad$ Cross analysis of gender and whether buses are used.

\begin{tabular}{|l|c|c|c|}
\hline & Male & Female & Total \\
\hline Takes the bus & $16(4.85 \%)$ & $27(8.18 \%)$ & $43(13.03 \%)$ \\
\hline Does not take the bus & $154(46.67 \%)$ & $133(40.30 \%)$ & $287(86.97 \%)$ \\
\hline Total & $170(51.52 \%)$ & $160(48.48 \%)$ & $330(100.00 \%)$ \\
\hline
\end{tabular}

Note: $\chi^{2}(1)=4.051>\chi_{0.05}^{2}(1)=3.841$; thus, $H_{0}$ (the two groups are independent) is rejected.

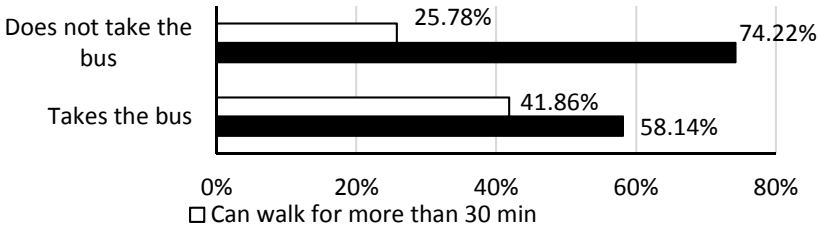

Figure 6: Walking ability among elders that take or do not take the bus. 


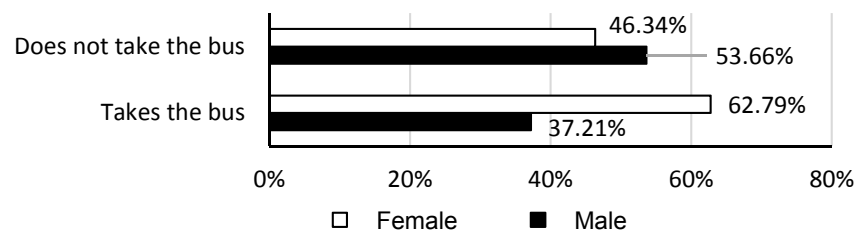

Figure 7: Gender and elders that take or do not take the bus.

\section{Activity time allocation of elderly people}

\subsection{Average time spent on activities}

We compared the average amount of time spent of elders in our survey results with the individual in Survey of Social Development Trends [19] (detail in Figure 8). Although the activity items used by the DGBAS somewhat differ from those used in this study, the compositions of the necessary physiological activities, mandatory activities, and leisure activities are the same.

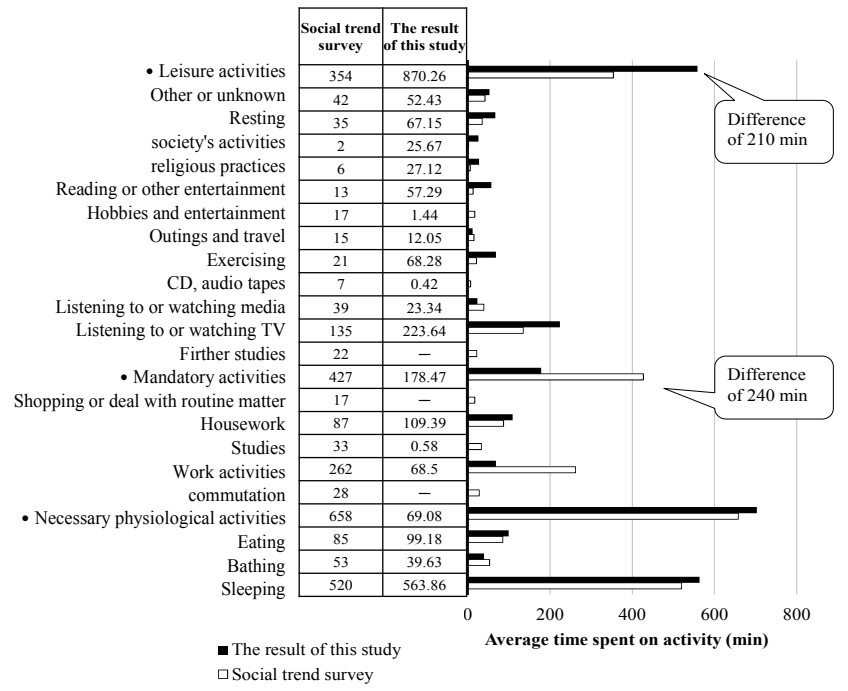

Figure 8: Line chart of time spent on various activities.

Elders spend more time on necessary physiological activities and leisure activities than individuals in other age groups. Being without the constraints of a routine work schedule, elders spend an average of 3 hours and 22 minutes more time on leisure activities than individuals in other age groups. The amounts of time spent on work and watching TV displayed the greatest differences. The mandatory activities of elders take 4 hours and 9 minutes less time than those of individuals in other age groups. Most of that difference is spent on housework. In 
conclusion, the elders in the study area spend approximately two fifths of the time spent by individuals in other age groups on mandatory activities, and nearly half of the time they spend on free activities is passed by watching TV.

\subsection{Desired activity time of elders}

The study conducted by Ohmori et al. [20] on the desired changes in activity times indicates that whether the elderly is employed impacts their desires regarding activity time. We therefore divided the participants based on employment. Figure 9 and Figure 10 display the details. The employed elders wished they could reduce the amount of time they spent on mandatory activities but increase the amount of time spent sleeping and on leisure activities. In contrast, unemployed elders mostly felt that the amount of time they were spending on various activities was sufficient, but they still wished to increase the amount of time spent on social activities and chatting.

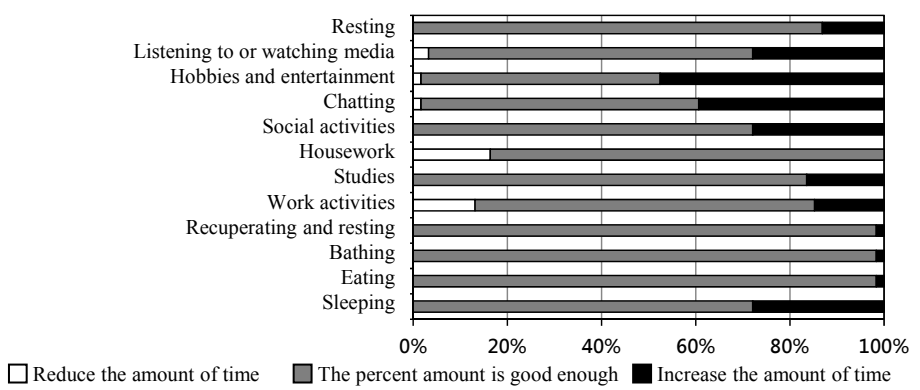

Figure 9: Desired changes in activity time by employed elders.

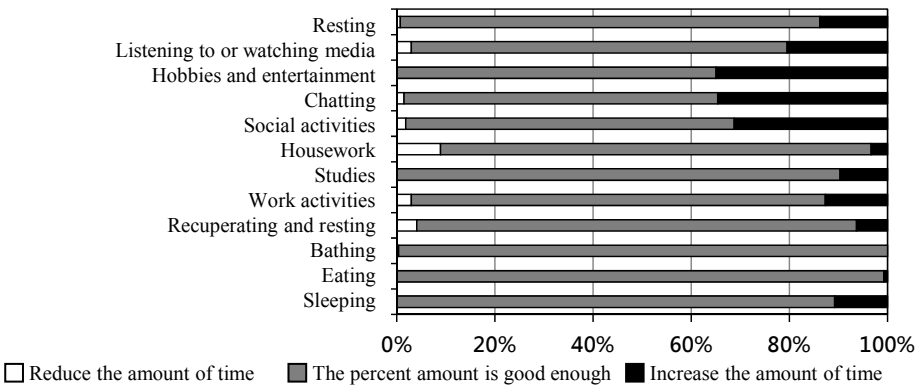

Figure 10: Desired changes in activity time by unemployed elders.

\section{Conclusion}

This study employed an activity-based approach to investigate the daily activities and transportation behaviour of elders in Tainan City. The analysis results led to three findings: (1) Mutual association exists among the age, walking ability, and 
activity (IADL score) of elders. Our results indicate that older elders tend to have poorer walking abilities and a greater degree of disability. (2) With regard to transportation behaviour, we found that (1) elders largely prefer private vehicles (accounting for $83.64 \%$ of the respondents), which mainly comprised scooters $(64.85 \%)$ and bicycles $(40.03 \%)$. However, whether they knew how to drive or ride private vehicles did not affect whether they took buses or taxis. (2) Overall, elders are relatively dependent on public transportation, but having poor walking abilities greatly decreases bus-riding behaviour. (3) On the whole, elders have an average of 3 hours and 22 minutes more time for leisure activities than individuals of other age groups. Nearly half of the time spent on leisure activities is passed by watching TV. It is concern that the employed elders wished they could reduce the amount of time they spent on mandatory activities but increase the amount of time spent sleeping and on leisure activities.

This study was primarily focused on (1) designing an activity diary survey, selecting the survey areas, and determining the survey locations as well as (2) constructing an activity/travel-activity behaviour database for elders and (3) understanding the connections among the activity/travel-activity behaviour variables of elders. We suggest that future research incorporate cluster analysis into the aforementioned variables to differentiate elders with different lifestyles. In addition, the activity diaries obtained in this study could be used to facilitate future micro-analysis of the transportation behaviour of elders within their potential activity range as well as macro-analysis of the differences between elders with different lifestyles.

\section{References}

[1] Council for Economic Planning and Development, Population Projections for R.O.C. (Taiwan): 2012 2060, Taipei: Council for Economic Planning and Development, 2012.

[2] Rosenbloom, S., Sustainability and automobility among the elderly: An international assessment. Transportation, 28, pp. 375-408, 2001.

[3] Zhou, M. and Lyles, R.W., Mobility patterns of the next generation of older persons. Transportation Research Record, 1573, pp. 99-104, 1997.

[4] Wan-hui Chen, Szu-wei Lee, A Study of Traffic Safety Issues of the Elderly and Their Comprehension of Traffic Safety Devices, Journal of Traffic Science, 4(1), pp. 31-46, 2004.

[5] Fong-Fu Lin, Traffic Crash Involved Elderly People, Taipei: Institute of Transportation, 2005.

[6] Burkhardt, J.E. and McGavock, A.T., Tomorrow's older drivers: Who? How many? What impact? Transportation Research Record, 1693, pp. 62-70, 1999.

[7] Wan-Hui Chen, Sheng-Hsiung Chang, Kui-Chuan Kao, Szu-Yu Lin, WanI Lin, Design and Evaluation of Bus Information at Bus Stops and Printed Information Brochures for the Elderly, Transportation Planning Journal, 38(4), pp. 355-380, 2009. 
[8] Li-Wei Cheng, Kevin P. Hwang, The Effects of Urban Public Transportation Service on Life Satisfaction of the Elders (Doctoral dissertation or master's thesis), National Cheng Kung University, 2008. Retrieved from http://etds.lib.ncku.edu.tw/etdservice/view_metadata? etdun=U0026-0812200914201322

[9] Wan-Hui Chen, Yuan-Ching Hsu, Pau-Ching Lu, Kui-Chuan Kao, Travel Characteristics and Demand Analysis for DRTS in Medical Trips for the Elderly, Journal of the Chinese Institute of Transportation, 21(3), pp. 329-353, 2009.

[10] Jen-Jia Lin, Ming-Shan Sie, What Are Elders' Needs for Urban Transportation Systems? A Case Study of Residents in Taipei Municipal Haoran Senior Citizens Home, Journal of Architecture and Planning, 9(2), pp. 101-122, 2008.

[11] Newbold, K., Scott, D., Spinney, J., Kanaroglou, P., and Páez, A., Travel behaviour within Canada's older population: a cohort analysis. Journal of Transport Geography, 13, pp. 340-351, 2005.

[12] Schmöcker, J., Quddus, M., Noland, R., Bell, M., Estimating trip generation of elderly and disabled people: an analysis of London data. Transportation Research Record: Journal of the Transportation Research Board, 1924, pp. 9-18, 2005.

[13] Páez, A., Scott, D., Potoglou, D., Kanaroglou, P., Newbold, K., A mixed ordered probit analysis of elderly trip generation in the Hamilton CMA. In: 11th International Conference on Travel Behaviour Research, Kyoto, 2006.

[14] Alsnih, R., Hensher, D. A., The mobility and accessibility expectations of seniors in an aging population, Transportation Research Part A, 37, pp. 903-916, 2003.

[15] Collia, D., Sharp, J., and Giesbrecht, L., The 2001 national household travel survey: a look into the travel patterns of older Americans. Journal of Safety Research, 34, pp. 461-470, 2003.

[16] Kemperman, A. and Timmermans, H.J.P., Influences of the built environment on walking and cycling of latent segments of the ageing population. Transportation Research Record: Journal of the Transportation Research Board, 2134, pp. 1-9, 2009.

[17] Ministry of Transportation and Communication, 2014, The daily use of transport Survey, Retrieved from http:/www.motc.gov.tw/ch/ home.jsp? id=54\&parentpath $=0,6$

[18] Wan-Hui Chen, Sheng-Hsiung Chang, The Study of Travel features and public transport information of aging society, Humanities and Social Sciences Newsletter Quarterly, 13(2), pp. 141-150, 2009.

[19] Ching-tsai Chen, Survey of Social Development Trends (Time Use), Taipei: Directorate-General of Budget, Accounting and Statistics, 2004.

[20] Ohmori, N., Muromachi, Y., Harata, N., and Ohta, K., A study on accessibility and going-out behaviour of aged people considering daily activity pattern, Journal of the Eastern Asia Society for Transportation Studies, 3 (5), pp. 139-153, 1999. 